\title{
A Facile Synthesis of Fe-doped Zirconium Oxide Nanoparticles for Enhancement of Rhodamine B Dye Degradation
}

\author{
Yuanfeng Hui*, Shuyue Zhang \\ College of resources and environment engineering, Jilin Institute of Chemical Technology, Jilin \\ 132022, China \\ *E-mail:huiyuranbaba@sina.com
}

doi: $10.20964 / 2021.06 .53$

Received: 5 March 2021 / Accepted: 13 April 2021 / Published: 30 April 2021

\begin{abstract}
This work presents a synthesis of undoped and Fe-doped zirconium oxide nanoparticles $\left(\mathrm{ZrO}_{2} \mathrm{NPs}\right)$ as photocatalyst for degradation of Rhodamine B dye (RB). The undoped and doped $\mathrm{ZrO}_{2}$ photocatalysts were successfully synthesized using co-precipitation process. Structural and morphological studies using XRD and FESEM showed that spherical shapes of undoped and Fe-doped $\mathrm{ZrO}_{2}$ NPs prepared in high crystallinity and tetragonal phase. The optical characterization of photocatalysts using UV-Vis absorbance spectra revealed that the band gap was increased with increasing the dopant concentration. The band gap values of 4.98, 4.44, 4.29, 4.05 and $3.88 \mathrm{eV}$ were obtained for undoped $\mathrm{ZrO}_{2}, 2 \mathrm{wt} \%$, $5 \mathrm{wt} \%$, $8 \mathrm{wt} \%$ and $10 \mathrm{wt} \% \mathrm{Fe}$-doped $\mathrm{ZrO}_{2} \mathrm{NPs}$, respectively, which indicates narrowing of band gap with increasing the $\mathrm{Fe}$ concentration. The results of photodegradation studies showed that the complete removal of $100 \mathrm{mg} / \mathrm{l} \mathrm{RB}$ was obtained after 55 minutes UV irradiation for the $8 \mathrm{wt} \% \mathrm{Fe}$-doped $\mathrm{ZrO}_{2}$. The maximum photodegradation efficiency on $8 \mathrm{wt} \%$ Fe-doped $\mathrm{ZrO}_{2}$ than undoped $\mathrm{ZrO}_{2}$ can be associated with the presence of $\mathrm{Fe}^{3+}$ ions that can act as a sink and trap and transfer holes and electrons to minimize recombination of photoexcited electrons and holes. The stability response of $8 \mathrm{wt} \% \mathrm{Fe}$-doped $\mathrm{ZrO}_{2}$ photocatalyst to degradation of Rhodamine B under UV irradiation showed that the photocatalyst had great recycling stability.
\end{abstract}

Keywords: Fe-doped zirconium oxide Nanoparticles; Photocatalyst; Rhodamine B; Photodegradation; Cycle voltammetry

\section{$\underline{\text { FULL TEXT }}$}

(C) 2021 The Authors. Published by ESG (www.electrochemsci.org). This article is an open access article distributed under the terms and conditions of the Creative Commons Attribution license (http://creativecommons.org/licenses/by/4.0/). 